\title{
Similar Gastric Emptying Rates for Casein- and Whey-Predominant Formulas in Preterm Infants
}

\author{
THORDUR THORKELSSON, FRANCIS MIMOUNI, RAN NAMGUNG, MARIANO \\ FERNÁNDEZ-ULLOA, SUSAN KRUG-WISPÉ, AND REGINALD C. TSANG
}

\author{
Department of Pediatrics, Division of Neonatology and Perinatal Research Institute, Children's \\ Hospital Research Foundation, Cincinnati, Ohio 45267-0541 /T.T., S.K.-W., R.C.T.]; \\ Department of Radiology, University of Cincinnati Medical Center, Cincinnati, Ohio 45267.0577 \\ [M.F.-U.]; Department of Pediatrics, Maimonides Medical Center, Brooklyn, NY 11219 [F.M.]; \\ and Department of Pediatrics, Yonsei University College of Medicine, Seoul, Korea 120-752 [R.N.]
}

\section{ABSTRACT}

\begin{abstract}
Casein-predominant infant milk formulas have been speculated to predispose to lactobezoar formation in preterm infants due to delayed gastric emptying. There have been, however, no prospective studies to prove this possibility. In a randomized, double-blinded, prospective study, we tested the hypothesis that preterm infants fed caseinpredominant milk formula have slower gastric emptying than infants fed whey-predominant formulas. Twenty preterm infants within the first $4 \mathrm{~d}$ of life were randomized to receive either the whey-predominant formula Similac Special Care (whey:casein ratio 60:40) or an experimental casein-predominant formula (whey:casein ratio 18:82). Only the protein composition differed between the two
\end{abstract}

formulas. The infants were fed the assigned study formula until they reached approximately $2200 \mathrm{~g}$ body weight when a gastric emptying scan was performed, using the designated study formula mixed with $25 \mu \mathrm{Ci}$ of technetium-99 sulfur colloid. Gastric emptying was followed continuously for $2 \mathrm{~h}$. Gastric emptying at $30,60,90$, and $120 \mathrm{~min}$ was similar between the two study groups. The time for $50 \%$ gastric emptying was $64.9 \pm 12.3 \mathrm{~min}$ for the infants fed the wheypredominant formula and $56.5 \pm 14.8 \mathrm{~min}$ for those fed the casein-predominant formula $(p=0.75)$. We conclude that the rate of gastric emptying in preterm infants fed caseinpredominant formulas is similar to that in those fed wheypredominant formulas. (Pediatr Res 36: 329-333, 1994)
Casein-predominant infant formulas have been speculated to cause lactobezoars in preterm infants (1). There have, however, been no prospective studies to prove this possibility. Initial reports on the association between casein-predominant formulas and lactobezoars in preterm infants were based on retrospective analyses, and subsequently all formulas specifically designed for preterm infants have been whey predominant. Although today most preterm infants are fed whey-predominant milk formulas, it is a common practice to discharge preterm infants home on regular formulas for term infants, some of which are casein predominant. Because there is a desire to send infants home earlier than in the past, these infants may therefore be changed to caseinpredominant formulas at a body weight as low as $1800 \mathrm{~g}$,

Received December 3, 1993; accepted April 6, 1994.

Correspondence and reprint requests: Thordur Thorkelsson, M.D., Department of Pediatrics, University of Cincinnati Medical Center, 231 Bethesda Ave., Cincinnati, OH 45267-0541.

Supported in part by a research grant from Ross Laboratories; and by the Procter Research Scholarship, Children's Hospital Medical Center and Children's Hospital Research Foundation, Cincinnati. which is within the weight range of previously reported cases of lactobezoar formation in preterm infants (2).

The pathophysiology of lactobezoar formation is inadequately understood but has been speculated to be related to slow rate of gastric emptying (2-4). In neonatal piglets, a milk formula consisting of $20 \%$ whey and $80 \%$ casein is evacuated slower from the stomach than formula containing $100 \%$ whey (5). It is therefore conceivable that casein-predominant formulas predispose to lactobezoar formation due to slow gastric emptying. In this study, we evaluated the effects of the protein composition of infant milk formulas on gastric emptying in preterm infants. In a randomized, double blind, clinical trial, we tested the hypothesis that preterm infants fed caseinpredominant formula have slower gastric emptying than infants fed whey-predominant formula.

\section{METHODS}

A randomized, double-blind study was conducted in preterm infants. Written consent was obtained from one parent before the infants were entered into the study. The study protocol was approved by the Institutional Review 
Board of Children's Hospital Medical Center and University Hospital of Cincinnati.

Subjects. Preterm infants were enrolled into the study based on the following inclusion criteria: 1) birth weight between 1800 and $2300 \mathrm{~g}, 2$ ) birth weight appropriate for gestational age [according to the gestational age scoring system of Ballard et al. (6) and using the intrauterine growth curves of Usher and McLean (7)], and 3) the infants had to be less than $4 \mathrm{~d}$ old when entering the study. Exclusion criteria were major congenital anomalies, abdominal distention, abnormal stools, jaundice (total bilirubin $>170 \mu \mathrm{mol} / \mathrm{L}$ ), and administration of theophylline, opiates, or antireflux medications. Infants receiving antibiotics were not excluded from the study. A total of 30 infants were enrolled into the study. Twenty infants completed the study. Ten infants were removed from the study for the following reasons: parental request (two infants), feeding intolerance (two infants), discharge from the hospital before gastric emptying scan could be performed (four infants), technical difficulties with the scintillation camera (one infant), and change from the $20-\mathrm{kcal} / \mathrm{oz}$ study formula to $24-\mathrm{kcal} / \mathrm{oz}$ formula because of a clinical concern of suboptimal growth (one infant).

Formula types. Upon study entry, the infants were randomized to receive either the whey-predominant formula Similac Special Care (Ross Laboratories; whey: casein ratio 60:40) or an experimental casein-predominant formula (whey:casein ratio 18:82). Only the protein composition differed between the two formulas. The nursing staff, medical staff, radiology technicians performing the gastric emptying scan, and the radiologist analyzing the gastric emptying data had no knowledge of the composition of the type of feeding to which an infant was assigned.

Gastric emptying scan. After randomization, the infants were fed the assigned study formula until they reached approximately $2200 \mathrm{~g}$, when a gastric emptying scan was performed. Those infants whose birth weight was more than $2200 \mathrm{~g}$ (four infants) had the gastric emptying scan done when they started to gain weight following the initial weight loss after birth. The age of the infants at the time of the gastric emptying scan ranged from 3 to $24 \mathrm{~d}$. The scan was performed 3 or $4 \mathrm{~h}$ after the previous meal, depending on the infant's feeding schedule. Immediately before the scan, the infants were fed the designated study formula $(20 \mathrm{~mL} / \mathrm{kg}$ body weight $)$ mixed with $25 \mu \mathrm{Ci}$ of technetium-99m sulfur colloid. The duration of feeding time was recorded for each infant and ranged from 7 to 33 min. Ethical concerns precluded the use of orogastric tube feeding. When the infant had consumed half of the formula, a 1-min image was obtained. This was done to facilitate the detection of the outline of the stomach during data analysis, before considerable gastric emptying had occurred. Upon finishing the whole feeding, the gastric emptying was followed by imaging continuously for $2 \mathrm{~h}$ with the infant lying in supine position on the scintillation camera. All information obtained by the gamma camera was transferred into a dedicated nuclear medicine computer and stored on a disk. Images were later recalled from the memory and areas of interest were assigned to each image encompassing the stomach as determined by the first image obtained during the study. Counts in each area of interest were recorded and used in calculating the percentage of gastric contents emptied at the various times. Decay corrections were used in all calculations.

Data analysis. The time zero for the gastric emptying time was defined as the time point when the infant started nippling the formula before the scan, as recommended by Elashoff et al. (8). This was done because some infants had considerable gastric emptying during feeding that would not have been included in the total gastric emptying if time zero was determined from the completion of feeding. Individual power exponential curves were fit to the fraction of feeding remaining in the stomach using the nonlinear regression method described by Elashoff et al. (8). The parameters estimated by this method were the time to $50 \%$ emptying and a parameter for the rate of gastric emptying.

Statistical methods. Statistical analysis was conducted with the SAS package, version 6.7 (SAS Institute, Inc., Cary, NC). Discrete variables were evaluated by $\chi^{2}$ analysis, or by Fisher's exact test when sample size was small. Continuous variables were evaluated by analysis of variance or nonparametric methods on ranked data when the data were not normally distributed. All hypothesis testing was two sided; a $p$ value of $<0.05$ was considered statistically significant. Data are expressed as mean \pm SEM.

\section{RESULTS}

Comparison of demographic data between the two groups is shown in Table 1. The only significant difference was uneven gender distribution between the two groups.

The average gastric emptying curves for the two study groups are shown in Figure 1. In all the study subjects, the power exponential model used provided a better fit than a linear model for each individual gastric emptying curve. There was no significant difference in the average

Table 1. Demographic and medical characteristics of study population by formula groups*

\begin{tabular}{lcc}
\hline & \multicolumn{2}{c}{ Formula type } \\
\cline { 2 - 3 } & $\begin{array}{c}\text { Whey } \\
\text { predominant }\end{array}$ & $\begin{array}{c}\text { Casein } \\
\text { predominant }\end{array}$ \\
\hline Gestational age (wk) & $33 \pm 0.3$ & $34 \pm 0.4$ \\
Apgar scores (5 min) & $8 \pm 0.4$ & $8 \pm 0.3$ \\
Gender (males/females) $\dagger$ & $2 / 8$ & $7 / 3$ \\
Race (white/black/other) & $2 / 8 / 0$ & $1 / 8 / 1$ \\
Age at study entry (d) & $1.8 \pm 0.3$ & $1.2 \pm 0.3$ \\
Weight at study entry (g) & $1981 \pm 56$ & $1989 \pm 41$ \\
Age when GES performed (d) & $13 \pm 2$ & $12 \pm 2$ \\
Weight when GES performed (g) & $2191 \pm 28$ & $2198 \pm 18$ \\
\hline
\end{tabular}

* Values are mean \pm SEM. GES, gastric emptying scan.

$\dagger p<0.05$. 


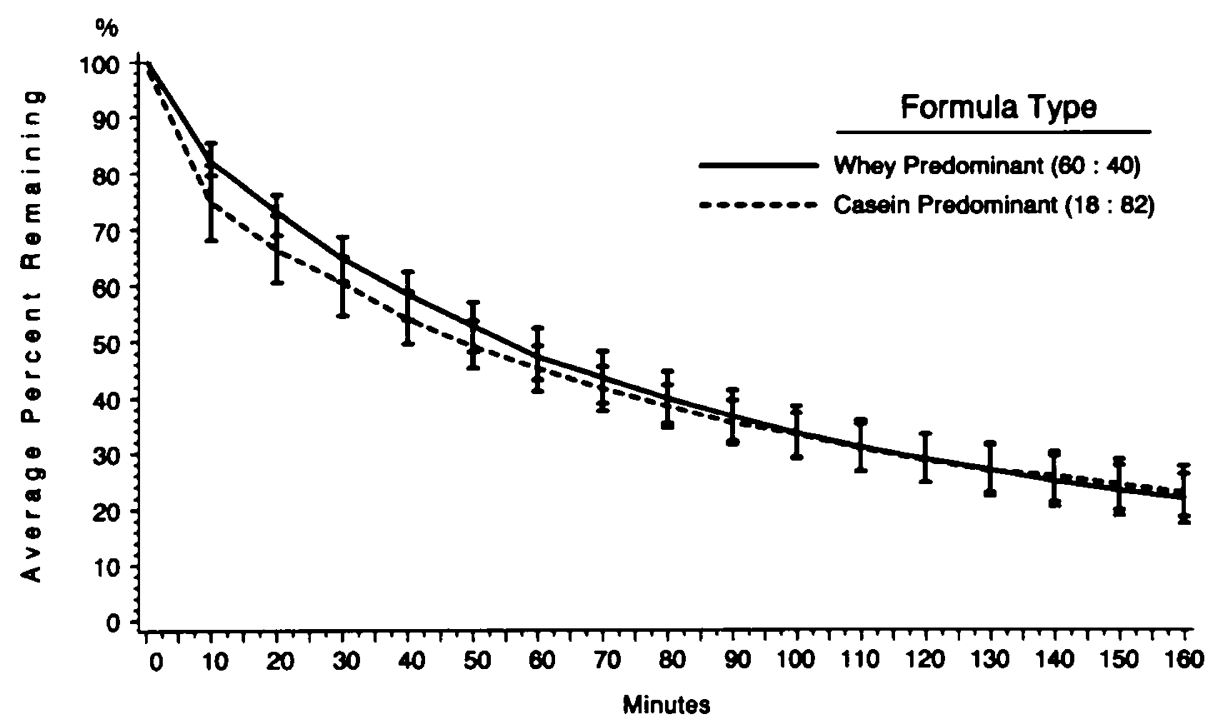

Figure 1. Average gastric emptying curves for the two study groups. The solid line represents the infants fed the whey-predominant formula and the broken line those fed the casein-predominant formula.

rate of gastric emptying between the two study groups. No significant difference in the amount of gastric emptying that had occurred by $30,60,90$, and $120 \mathrm{~min}$ was found between the two feeding groups (Table 2). Sample size of 10 infants in each group gives $80 \%$ power to detect a difference of $18 \%$ in gastric emptying between the two groups at each of the four time points investigated at an alpha level of 0.05 .

The time at which $50 \%$ of gastric emptying had occurred was not significantly different between the wheypredominant $(64.9 \pm 12.3 \mathrm{~min})$ and the casein-predominant $(56.5 \pm 14.8 \mathrm{~min})$ groups $(p=0.75)$.

Both formulas were equally well tolerated. No instance of lactobezoar was observed.

\section{DISCUSSION}

Initial reports of lactobezoars in newborn infants were primarily full-term infants being fed inappropriately diluted powdered milk formulas $(9,10)$. In the late 1970 s, there were several reports suggesting an increase in the incidence of lactobezoars in preterm infants $(3,4,11,12)$. The cause for this increase was not known but was speculated to be related to the use of formulas designed at that time for preterm infants (especially $24-\mathrm{kcal} / \mathrm{oz}$ for-

Table 2. Percentage gastric emptying at 30,60, 90, and $120 \mathrm{~min}^{*}$

\begin{tabular}{rcc}
\hline & \multicolumn{2}{c}{ Formula type $(\%)$} \\
\cline { 2 - 3 } & $\begin{array}{c}\text { Whey } \\
\text { predominant }\end{array}$ & $\begin{array}{c}\text { Casein } \\
\text { predominant }\end{array}$ \\
\hline $30 \mathrm{~min}$ & $35 \pm 4$ & $40 \pm 5$ \\
$60 \mathrm{~min}$ & $52 \pm 5$ & $55 \pm 4$ \\
$90 \mathrm{~min}$ & $63 \pm 5$ & $64 \pm 4$ \\
$120 \mathrm{~min}$ & $71 \pm 5$ & $71 \pm 4$ \\
\hline
\end{tabular}

* Values are mean \pm SEM. No significant differences were found in the amount of gastric emptying between the two groups at each time point. mulas), the mode of feeding, or the protein composition of the formulas. In 1980, Erenberg (2) reviewed the first 33 cases of lactobezoars reported in preterm infants. All of these infants had been fed casein-predominant formulas (whey:casein ratio 20:80). Schreiner et al. (1) subsequently reported lactobezoars in 29 infants, all of whom had been receiving casein-predominant formulas. This observation made these authors conclude that feeding the preterm infant casein-predominant formulas predisposes to lactobezoar formation. However, lactobezoars were later reported to occur in preterm infants fed wheypredominant formulas (13) and also human milk (14). Whether feeding preterm infants casein-predominant formulas predisposes to lactobezoar formation has, however, not been investigated prospectively.

One of the main risk factors for lactobezoar formation appears to be low birth weight. The mean birth weight of the lactobezoar cases reviewed by Erenberg (2) in 1980 was $1318 \mathrm{~g}$ with the range from 794 to $2530 \mathrm{~g}$. The incidence of lactobezoars appears also to be directly related to the degree of prematurity (2). Why preterm infants are at greater risk for lactobezoar formation than term infants is, however, not known. The mechanism for lactobezoar formation is inadequately understood. It has been speculated that delayed gastric emptying might predispose to lactobezoar formation $(3,4,12)$. Healthy preterm infants appear to have a gastric emptying rate similar to that of full-term infants (15), but certain neonatal diseases such as jaundice and respiratory distress syndrome have been shown to be associated with delayed gastric emptying $(15,16)$. Preterm infants are also frequently nursed in supine position, which has been shown to be associated with delayed gastric emptying (15).

The nutritional composition of the feeding has been shown to affect the rate of gastric emptying in both animal and human studies (17). In neonatal piglets a milk formula consisting of $20 \%$ whey and $80 \%$ casein emptied 
more slowly from the stomach than formula containing pure whey (5). The effects of casein-predominant milk formulas on gastric emptying in humans have mainly been evaluated in children with gastroesophageal reflux. Billeaud et al. (18) evaluated gastric emptying of different types of milk in infants less than $1 \mathrm{y}$ of age, with or without gastroesophageal reflux. They found that infants fed casein-predominant formulas had 50\% slower gastric emptying than those fed human milk, 34\% slower emptying than those fed whey-predominant formula, and $47 \%$ slower emptying that those fed whey-hydrolysate formula. Tolia et al. (19) found that infants between 1 and 11 mo of age with gastroesophageal reflux who were fed casein-predominant formula had $18 \%$ slower gastric emptying than those fed whey hydrolysate formulas. Fried $e t$ al. (20) demonstrated that 3- to 18-y-old patients with spastic quadriplegia and a history of regurgitation fed whey-based formulas had a $43 \%$ shorter gastric emptying time than when they were fed casein-predominant formula. These studies thus support the theory that feeding young human subjects casein-predominant milk formulas results in slower gastric emptying than when they are fed milk that has whey as the predominant protein. The limitation of these studies, however, is that they were not controlled for the amount of other nutrients in the types of milk evaluated, which are known to affect the rate of gastric emptying in humans $(21,22)$. For example, medium-chain fatty acids have been shown to empty faster from the stomach than long-chain fatty acids, and glucose and lactose empty slower than glucose polymers in preterm infants (21). Nonisotonic duodenal contents have been shown to slow gastric emptying in adults (22).

Due to the low $\mathrm{pH}$ of gastric juice, casein forms curds in the stomach but whey remains in liquid form (23). In adults, solids empty more slowly from the stomach than liquid meals (24). Solids have also been shown to have linear gastric emptying in adults, whereas liquid meals empty exponentially from the stomach (24). It has been speculated that casein empties from the stomach more like solids than liquids, which might result in delayed gastric emptying (19). This speculation is not supported by the findings in our study, where both the casein- and the whey-predominant formulas had similar gastric emptying patterns that fitted an exponential model equally well.

Until now, no study has evaluated the effects of the protein composition of commercially available milk formulas on gastric emptying in preterm infants. In this study, we demonstrated a similar rate of gastric emptying in preterm infants fed casein- or whey-predominant formulas. These findings are therefore not in accordance with previous studies on children past the neonatal period, in whom it appears that feeding casein-predominant formulas results in delayed gastric emptying. This could conceivably be due to the fact that in this study we controlled for the potential confounding effects of other nutrients in the formulas. Only the protein composition differed between the two formulas, and the amount of all other nutrients and the osmolality were the same. Our data therefore do not support the hypothesis that caseinpredominant formulas predispose to lactobezoar formation in preterm infants due to delayed gastric emptying. From this study we can only conclude that caseinpredominant formulas do not result in delayed gastric emptying compared with whey-predominant formulas. We cannot conclude whether preterm infants fed caseinpredominant formulas are at greater risk of developing lactobezoar than those fed whey-predominant formulas. To determine the effects of these two types of formulas on lactobezoar formation, a larger sample size would be needed, because the occurrence of lactobezoar is relatively uncommon. Schreiner et al. reported the incidence of lactobezoar in infants less than $2000 \mathrm{~g}$ to be between 0.2 and $6.5 \%(1,2)$. None of the infants in our study developed lactobezoar, presumably because the occurrence of lactobezoar is relatively uncommon. Another reason might be that these infants were relatively large, because the incidence of lactobezoar formation in preterm infants appears to be inversely related to their birth weight (2). The duration of feeding of the study formula should have been long enough to allow lactobezoar formation in the infants in our study. Most of the infants were fed the study formula for between 1 and 2 wk (Table 1). In the 33 cases of lactobezoar reported by Erenberg (2) in 1980 , the mean age $( \pm 1 \mathrm{SD})$ at diagnosis was $12 \pm 9 \mathrm{~d}$.

The demographic characteristics of the two study groups were similar, as shown in Table 1. The only significant difference was uneven gender distribution between the two groups. This difference is not expected to influence the result of the study, because gender is not known to affect the rate of gastric emptying.

In summary, we have shown that casein- and wheypredominant milk formulas have similar gastric emptying rates in preterm infants, when the effects of all other nutrients in the formulas on gastric emptying are controlled for. We speculate therefore that the cause of lactobezoars in preterm infants fed commercially available infant formulas is not related to the effects of the milk proteins on gastric emptying. If milk proteins relate to lactobezoar formation, as suggested by various authors, it is likely to be via a mechanism different from affecting the rate of gastric emptying.

\section{REFERENCES}

1. Schreiner RL, Brady MS, Ernst JA, Lemons JA 1982 Lack of lactobezoars in infants given predominantly whey protein formulas. Am J Dis Child 136:4374.39

2. Erenberg A 1980 Lactobezoar. In: Sunshine $P$ (ed) Feeding the Neonate Weighing Less Than 1500 Grams: Nutrition and Beyond. Proceedings of the Seventy-ninth Ross Conference on Pediatric Research. Ross Laboratories, Columbus, OH, pp 1902-202

3. Schreiner RL, Brady MS, Franken EA, Stevnes DC, Lemons JA, Gresham EL 1979 Increased incidence of lactobezoars in low birth weight infants. Am J Dis Child 1.33:936-940

4. Grosfeld JL, Schreiner RL, Franken EA, Lemons JA, Ballantine TVN, Weber TR 1980 The changing pattern of gastrointestinal bezoars in infants and children. Surgery $88: 425-432$

5. Newport MJ, Henschel MJ 1985 Growth, digestion and protein metabolism in neonatal pigs given diets containing whey as the predominant or only source of milk protein. J Pediatr Gastroenterol Nutr 4:639-644 
6. Ballard JL, Noval KK, Driver MA 1975 A simplified score for assessment of fetal maturation in newly born infants. J Pediatr 95:769-774

7. Usher R, McLean F 1969 Intrauterine growth of liveborn Caucasian infants at sea level: standards obtained from measurements in seven dimensions of infants born between 25 and 44 weeks of gestation. J Pediatr 74:9011919

8. Elashoff JD, Reedy TJ, Meyer JH 1982 Analysis of gastric emptying data. Gastroenterology 83:1306-1312

9. Wolf RS, Davis LA 1963 A foreign body formed by the use of undiluted powdered milk substance. JAMA 184:782

10. Majd M, LoPresti JM 1972 Lactobezoar. Am J Roentgenol Radium Ther Nucl Med 116:575-576

11. Duritz G, Oltorf C 1979 Lactobezoar formation associated with high-density caloric formula. Pediatrics 63:647-649

12. Erenberg A, Shaw RD, Yousefzadeh D 1979 Lactobezoar in the low-birthweight infant. Pediatrics 63:642-646

13. Barness LA, Curran JS 1982 Lactobezoar in infants [letter]. Am J Dis Child 136:1929-1930

14. Yoss BS 1984 Human milk lactobezoars. J Pediatr 105:819-822

15. Yu VYH 1975 Effect on body position on gastric emptying in the neonate. Arch Dis Child 50:500-504

16. Costalos C, Russell G, Bistarakis L, Pangali A, Philippidou A 1984 Effects of jaundice and phototherapy on gastric emptying in the newborn. Biol Neonate $46: 57-60)$

17. Lebenthal E, Siegel M 1985 Understanding gastric emptying: implications for feeding the healthy and compromised infant. J Pediatr Gastroenterol Nutr 4:1-3

18. Billeaud J, Guillet J, Sandter B 1990 Gastric emptying in infants with or without gastro-(resophageal reflux according to the type of milk. Eur J Clin Nutr 44:577-583

19. Tolia V, Lin CH, Kuhns LR 1992 Gastric emptying using three different formulas in infants with gastroesophageal reflux. J Pediatr Gastroenterol Nutr 15:297-301

20. Fried MD, Khosoo V, Secker DJ, Gilady DL, Ash JM, Pencharz PB 1992 Decrease in gastric emptying time and episodes of regurgitation in children with spastic quadriplegia fed a whey-based formula. J Pediatr 120:569-572

21. Siegel M, Krantz B, Liebenthal E 1985 Effect of fat and carbohydrate composition on the gastric emptying of isocaloric feedings in premature infants. Gastroenterology 89:785-79()

22. Meeroff JC, Go VLW, Phillips SF 1975 Control of gastric emptying by osmolality of duodenal contents in man. Gastroenterology 68:1144-1151

23. Nakai S, Li-Chan E 1987 Effect of clotting in stomachs of infants on protein digestibility of milk. Food Microstructure $6: 161-170$

24. Minami H. McCallum RW 1984 The physiology and pathophysiology of gastric emptying in humans. Gastroenterology 86:1592-1610 